\title{
A Review of the Concepts and Measurements for Connection to Nature and Environmentally Responsible Behaviour-a Call for Research on Human-Forest Relationships
}

\author{
Liina Häyrinen ${ }^{1} \cdot$ Sari Pynnönen ${ }^{2}$ \\ Published online: 8 October 2020 \\ (C) The Author(s) 2020
}

\begin{abstract}
Purpose of Review The review examines recent scientific discussion on the concepts and measurements of human connection to nature $(\mathrm{CTN})$ and pro-environmental behaviour (PEB). In addition to that, we explore the environmental contexts in which study populations are exposed to nature or nature experiences, particularly the contexts in which forests emerge from these studies, and lastly outline gaps in research.

Recent Findings Outlining the association between CTN and PEB has been widely researched over the past 5 years. The concepts and measurements referring to these terms vary, but a few commonly used concepts were identified. The review classifies the approaches used for exploring the relationship between CTN and PEB into four categories. The review indicates that the interconnection between CTN and PEB is mostly studied as a part of the wider concept. Approximately half of the reviewed articles explored the actual exposure to some natural environment or nature activity either directly or indirectly. Forests only played a small role as a natural environment in the reviewed articles.

Summary Forests appear to be of very little weight or under-represented in CTN and PEB literature as an explicitly identified natural environment. Results also indicate that the human-forest relationship has not been defined precisely in empirically based scientific literature. The paper discusses implications for the future research focusing on emphasizing the role of forests as natural environments in the research of CTN and PEB.
\end{abstract}

Keywords Sustainable behaviour $\cdot$ Forest relationship $\cdot$ Connection to forests $\cdot$ Nature connection $\cdot$ Connectedness to nature

\section{Introduction}

Understanding the drivers for human pro-environmental behaviour (PEB) is becoming increasingly important when considering the goals set towards sustainable future development. Human connection to nature is a concept that contributes to explaining PEB and human well-being. In recent decades, human connectedness to nature and its association with PEB

This article is part of the Topical Collection on Forest Policy, Economics and Social Research

Liina Häyrinen

liina.hayrinen@luke.fi

1 Natural Resources Institute Finland (Luke), Latokartanonkaari 9, 00790 Helsinki, Finland

2 Department of Forest Sciences, University of Helsinki, Latokartanonkaari 7, 00014 Helsinki, Finland has been studied (e.g. [1-4]) especially in the field of environmental psychology (e.g. [5]). One of the most cited works in the field, Mayer and Franz [6] introduced the concept of "connectedness to nature", defined as "individuals' affective, experiential connection to nature". Restall and Conrad [2] defined connectedness to nature as "understanding how people identify themselves with the natural environment and the relationships they form with nature". Forests in particular have gained importance as providers of multiple ecosystem services important in mitigating the adverse effects of climate change to human well-being. Thus, attitudes towards their use and preservation are of special interest.

The human-nature relationship can generally be defined as the way human beings or societies perceive nature and the environment around them. It is foremost a worldview, an ethical and philosophical phenomenon. A nature relationship describes attitudes or ways of thinking about nature rather than a concrete way of interacting with it [7]. Human connection to nature is considered as a rather stable trait that does not change 
much over time or situations [8] although people may temporarily feel more connected to nature after being exposed to it too [9]. Rossi [10] defines the human relationship to the environment as everything humans do to their environment (both natural and built), within it or because of it, as an individual or as a society. This includes observations, feelings, and experiences of, and attitudes and actions towards the environment, and their outcomes. Human-environment relationships in a society reflect the social structures and ideologies of those societies [11].

Several different terms and measurement scales have been defined in the literature to describe human connection with nature. According to Whitburn et al. [12•], measurement items capturing the relationship between humans and nature can be divided into three interrelated dimensions: the affective dimension reflects feelings towards nature, the cognitive dimension captures knowledge and beliefs about nature and the behavioural (or experiential) dimension relates to actions and experiences in nature. Schultz's [9] approach is cognitive, and he states "connectedness [to nature] refers to the extent to which an individual includes nature within his/her cognitive presentation of self'. On the other hand, the concept of nature relatedness by Nisbet et al. [8] captures dimensions from affective, cognitive to experiential aspects. Thus, concepts and measurement scales that represent connection to nature may be unidimensional $[6,9]$ or multidimensional such as environmental identity (EID) [13] or nature relatedness [8]. Furthermore, a variety of other terms also refer to a similar construct with connection to nature, such as love and care for nature [14], connectivity with nature [15], emotional affinity towards nature [1] and dispositional empathy with nature [16]. When we discuss nature connection at a general level in this article, without specifically referring to any concept or scale developed by scientists, we use the more general term connection to nature (CTN).

Various concepts and scales employed to define or measure an individual's connection to the natural world are partly overlapping. Hence, they may be highly intercorrelated and accordingly considered markers of a common construct [3]. Thus, connection to nature may be considered a broader construct encompassing various concepts, although we must keep in mind that the theories are not completely identical [3]. According to the meta-analysis by Whitburn et al. [12•], multidimensional measurement scales capture more aspects of nature connection and may thus be better associated with PEB than unidimensional constructs. Further, Restall and Conrad [2] state that connectedness to nature has established as a leading term for the construct.

Similarly, concepts and scales to measure environmental attitudes and behaviour vary in the literature. Certain ones are validated and properly tested such as the ecology scale by Maloney et al. [17] (see also [18, 19]). Measuring PEB is usually based on self-reporting, as measuring it objectively is difficult $[12,20,21]$. Some measurement scales may be interpreted to include multiple dimensions, allowing them to function as measures of both CTN and PEB. For example, the EID scale is a multidimensional scale with sub-dimensions that correlate differently with nature connection, while other scales better predict PEB [22]. This review paper adapts the definition of PEB from Steg and Vleg [23], in which the environment is harmed as little as possible or even benefits from the behaviour. Intentions are generally agreed to be a significant indication of behaviour [24, 25], and environmental attitudes and behaviour have also been found to positively link with each other [26, 27॰]. More broadly, we define PEB as actions, attitudes and intentions that contribute or promote the well-being of nature around us. Schultz [9] has argued that connectedness with nature leads to caring for it, which accordingly results in the commitment to protect nature. Whitburn et al. [12•] suggest longitudinal studies to demonstrate causation between CTN and PEB.

Nature contact or exposure refers to physical contact with nature, whereas nature connectedness or connection is considered a psychological contact [28]. Relationships between exposure to nature (ETN), CTN and PEB are interrelated [29]. While outdoor recreation is indicated to associate with a higher PEB level (e.g. [30]), ETN has also been linked to increased levels of CTN and PEB [31]. Human exposure to natural environments may increase their connection with nature even in the short term [32]. However, association between ETN and PEB has not been robust in all previous studies, but there has been more solid link between connection to nature and PEB [4•]. In addition, ETN has positive effects on human health and well-being (e.g. [33-35]) and also CTN is associated e.g. with happiness and psychological well-being [36, 37]. According to Wyles et al. [38], certain natural environments may be more beneficial to psychological restoration compared with other environments. The authors found also that certain types and qualities of natural environments have a greater impact on the connectedness to nature felt by humans in England.

When referring to the human-nature relationship in countries where people have easy access to forests because of forest abundance and national culture, such as Finland and Sweden, the human-forest relationship may well be more relevant than the relationship to nature in general [39, 40]. Nonetheless, forest relationship can also be understood as a sub-concept of the nature relationship [10]. Similarly to other natural environments, the importance of forests as a source of human well-being is recognized in previous literature [41, 42]. Forest may have both physiological and psychological effects on human health and even short-term exposure to forests has relaxing effects [43]. However, literature on the human-forest connection and its association to PEB is scarce. In the context of forest environments, Nord et al. [44] reported a link between forest recreation activity and PEB, but contradictingly 
indicated that the association between recreation and environmental concern was weak. In the case of family forest owners in Finland, Häyrinen et al. [45] found that owners with the highest pro-environmental orientation appreciated the nature, health and heritage values of forests more compared with other owners, which may also reflect their closer connection to nature.

Several studies indicate a clear link between human connection to nature and PEB. Reviewing how the associations between CTN and PEB have been studied and in particular, how forests as natural environments are discussed in this scientific literature is of great interest. The purpose of this review is to examine a recent scientific discussion on the concepts of CNT and PEB and to outline gaps in research. This study systematically reviews empirical studies from the past 5 years employing a content analysis approach and explores the contexts that forests emerge from in research concerning the relationship between connection to nature and PEB. Research on human connection to nature has got increasingly common particularly in last years, although it has started already earlier (e.g. [6, 46]). More specifically, we explore (1) the terminology, measurement scales and approaches that have been employed to explore the concepts of CTN and PEB and their interconnection; (2) how and in which environmental contexts studied populations are exposed to nature or nature experiences and (3) the contexts that forests emerge from in these studies.

\section{Data and Analysis Method}

\section{Planning of Data Collection and Search Strategy}

This review was conducted following the typical protocols of carrying out a literature review (e.g. [47, 48]). The Scopus database was employed to select the comprehensive collection of research articles needed for the review.

At the first stage of the review process, search terms and their combinations were defined based on previous literature and expertise jointly by the authors of this review. Selecting the articles into the review included various steps. We started by exploring the previous literature on the theme and ended up with 18 search terms or expressions.

Five search terms were included describing the human-nature relationship and that have been employed in several previous studies: connectedness to nature, connection with nature, nature connectedness, nature relatedness and connection to nature. Furthermore, we decided to select 13 search words or combination of words that were combined with CTN terms: sustainable behaviour, pro-environmental, pro-environmental behaviour, proenvironmental, consumption, ecological, ecological behaviour, conservation, environmental, environmental behaviour, environmental identity, environmentally friendly and environmentally responsible. The steps for selecting the articles in the review are presented in Fig. 1. Other search terms from the previous literature were also considered prior to final selection: love and care for nature, connectivity with nature, emotional affinity towards nature, dispositional empathy with nature and inclusion of nature in the self (e.g. [1, 9, 14-16]). These search terms were excluded due to the relatively small number of hits and after a closer look at the titles and abstracts. As the focus of our study is particularly on measurement scales, search terms emphasize the concepts employed more in quantitative studies.

"Forests" and "woods" were also tested in connection to the main search terms, but no relevant studies were found with this combination. Thus, these search terms were intentionally excluded to keep the focus of the review on the concepts of $\mathrm{CTN}$ and PEB. We decided to scrutinize the emergence of forests in the CTN and PEB studies only in the analysis phase of the articles using the content analysis approach.

\section{Study Inclusion and Exclusion Criteria}

A 5-year scope was selected for the review to ensure capturing the recent development of the discussions. Therefore, we included articles from 2015 to 2020 (21.2.2020). For consistency of the review data, we only selected peer-reviewed articles and thus, excluded book chapters, conference papers, grey literature and other review papers. In addition, only articles written in English and research articles based on primary data were assessed and included in the analysis.

Whether a paper deals with the relationship between humans and natural environments that is at some level linked to PEB was the main criterion for including a specific study for the analysis. To be included, the connection between CTN and PEB did not have to be the main theme of the article as long as their connection was considered at some level. An article was also accepted into the analysis if the association between CTN and PEB was descriptive (e.g. qualitative interview). It also did not matter whether $\mathrm{CTN}$ influenced $\mathrm{PEB}$ or PEB affected CTN.

Forms of PEB and its various actions are understood widely in this review. Hence, articles that indicate e.g. behaviour, actions, conservation support, conservation engagement, attitudes or intentions are all considered in the review. However, a study was excluded from the final set of articles if it only handled, e.g. environmental concern without actual actionrelated aspects. In addition, articles did not need to directly explore the relationship between CTN and PEB if they were both examined in relation to nature exposure. 
Fig. 1 Stages of article search

\begin{tabular}{|c|c|c|c|c|}
\hline \multicolumn{5}{|c|}{$\begin{array}{l}\text { STAGE 1: } \\
\text { the selected search terms found } 281 \text { articles in Scopus for Jan 2015- Feb } 2020\end{array}$} \\
\hline $\begin{array}{l}\text { connectedness } \\
\text { to nature }\end{array}$ & $\begin{array}{l}\text { connection with } \\
\text { nature }\end{array}$ & $\begin{array}{l}\text { nature } \\
\text { connectedness }\end{array}$ & $\begin{array}{l}\text { nature } \\
\text { relatedness }\end{array}$ & $\begin{array}{c}\text { connection to } \\
\text { nature }\end{array}$ \\
\hline \multicolumn{5}{|c|}{$\begin{array}{l}\text { pro-environmental } \\
\text { pro-environmental behaviour } \\
\text { proenvironmental } \\
\text { consumption } \\
\text { ecological } \\
\text { ecological behaviour } \\
\text { conservation } \\
\text { environmental } \\
\text { environmental behaviour } \\
\text { environmental identity } \\
\text { environmentally friendly } \\
\text { environmentally responsible }\end{array}$} \\
\hline \multicolumn{5}{|c|}{$\begin{array}{l}\text { STAGE 2: } \\
\begin{array}{c}\text { Exclusion criteria: no books or grey literature, no reviews and meta-analyses; papers with no } \\
\text { relevance for the review }\end{array}\end{array}$} \\
\hline \multicolumn{5}{|c|}{102 articles were examined further } \\
\hline Exclusion criteris & papers with sever & $\begin{array}{l}\text { STAGE 3: } \\
\text { sub-studies, pape } \\
\text { for PEB }\end{array}$ & thout actual ac & elated aspects \\
\hline
\end{tabular}

\section{Conducting the Article Search}

The search terms used in stage 1 were set into the box of abstracts, titles and keywords in Scopus (see the used search code in Appendix 1). The defined search terms resulted in 281 hits that were selected for screening. At this stage, no selection was made regarding the category of literature (e.g. article, book chapter etc.) to ensure that all relevant studies were found. In stage 2 , i.e. the abstract-reading stage, articles were quite easily included for further reading to make sure no relevant studies were excluded only based on their abstract. From 281 tentatively selected articles, 102 papers were selected for further reading based on their abstracts. In stage 3, the selected 102 articles were further scanned. To facilitate the interpretation of the articles, we also removed papers with more than one sub-study or if the paper mainly tested and developed measurement instruments. Finally, 48 articles were included in the actual full-text screening and analysis of the literature review and were transferred to the Atlas.ti-software.

\section{Coding and Analysis of the Reviewed Articles}

Atlas.ti was employed to analyse the selected 48 articles. To enhance analysis reliability, part of the analyses were conducted jointly and discussed by the authors at various phases of the analysis. The analysis was conducted as content analysis, aiming to describe and quantify the phenomena of interest $[49,50]$. Because of the large number of articles included in the review and the objectives of our inquiry, the analysis concentrated mainly on the manifest content of the articles [49]. We first coded the reviewed articles according to a coding scheme developed to answer the research questions and then calculated the frequencies of the identified contents.

To describe the general features of the reviewed articles, we identified the geographical distribution, data collection method and study population of each article. As for the conceptual features, terms used in an article to describe CTN and PEB were identified. Because terms were also used interchangeably or in parallel in many articles, we aimed to extract one or two of the most commonly used terms for these concepts. In addition, measurement scales or methods that were employed to measure an individual's connection to nature or PEB were identified if justified. For example, clear identification of the CTN and PEB measures was not possible in most of the qualitative studies. The environmental context and mode of nature exposure were also noted from the study, if reported. To report the links between CTN and PEB, we aimed to identify how the study viewed, measured or otherwise dealt with the association between CTN and PEB. The particular aim of the review was to explore the approaches that have been used in the studies, and hence, we did not list the results of individual studies. Most importantly, to identify how forests appear in the reviewed articles, we searched for words such as forests, forestland, woods and woodland. 


\section{Results}

\section{General Description of Reviewed Articles}

A list of articles included in the analysis and a summary of the main contents identified are presented in Appendix 2 (Table 2 ). Studies were conducted in 23 countries. Most were conducted in Europe (33\%) and North America (31\%). The remaining studies were located in Oceania (13\%), Asia (10\%) and South America (4\%). A few studies were also conducted on two or more continents. Studied populations were mainly adults ( $73 \%$ of all studies). Adults were often residents or citizens of certain areas or visitors of various nature sites. Undergraduate students were (19\%) the second most popular study population. School children and adolescents together represented $8 \%$ of the reviewed sample. ${ }^{1}$ The data collection method was divided into three categories: quantitative, qualitative and mixed methods. Most of the reviewed articles used a quantitative approach to collect their data (77\%). Mixed methods (application of both quantitative and qualitative approaches) were used in $19 \%$ of the studies. Only $4 \%$ of studies could be classified into a purely qualitative category. Data collection in $38 \%$ of the studies consisted of several consecutive phases or the data comprise of several parts (e.g. pre- and post-questionnaire).

\section{CTN and PEB Concepts and Instruments}

Varied terminology was used to describe the human connection to nature, and various forms of the term were used even within a single article. As expected from the search terms used to search the literature, three popular expressions emerged clearly. However, we aimed to choose the expression that an article mainly used. Consequently, connectedness to nature was the most popular expression used to describe human connection to nature in the reviewed articles. It accounted for $54 \%$ of the total number together with nature connectedness, which was frequently used interchangeably with connectedness to nature. Connection to (or with) nature was the second most popular term, with a share of $27 \%$. Nature relatedness, in turn, was used in $15 \%$ of the articles. Connectedness with nature, which was a combination of the former terms, appeared a few times.

Pro-environmental behaviour was the term used for PEBrelated activities in most of the reviewed articles (52\%). However, expressions used to describe human PEB, such as sustainable behaviour or ecological consumption, varied widely from one article to another. The terms varied even within a single article. Altogether, we found approximately

\footnotetext{
${ }^{1}$ School children are interpreted mainly as under 15 -year-old children and adolescents as under 21 year-olds, as education systems differ between countries.
}

20 expressions for PEB in the reviewed articles. The majority of articles contained more general terms (e.g. environmentally friendly or conservation behaviour), but quite specific actions were also reported (e.g. environmental action and conservation support).

The scales and items that measured the concepts of CTN and PEB were also varied. The 14 statements of the Connectedness to Nature scale (CNS) [6] and its modifications were the most popular way to measure CTN (used in $38 \%$ of the articles). The second most employed measure was the Inclusion of Nature in Self scale (INS) [9, 51], which was used in $19 \%$ of the reviewed articles. In addition, The Nature Relatedness scale and its shorter form [8, 52] were represented in $15 \%$ of the articles. Furthermore, other validated measurement items or scales were also employed such as the Love and care for nature scale [14], the Disposition to connect with nature scale [53] and the Environmental Identity scale (also containing dimension of PEB) [13] (27\%). No actual measurement scales were used in the studies that utilized a qualitative approach, such as interviews, and CTN was therefore interpreted by the authors of this article. The most popular scales, such as CNS and INS, were also used in parallel in a few articles (see Appendix 2 (Table 2) for further details).

Scales or measurements utilized to depict PEB varied widely, as we interpreted PEB in a broad manner (see inclusion criteria). Variation in the scales was much larger than for the CTN measurements. Most of these measurement scales or items were adapted or modified from previous studies $(56 \%)$. In these articles, a few measurement scales emerged more frequently. The General Ecological Behavior scale (GEB) $[18,54]$ and its modifications and the Behavior-based Environmental Attitude scale [55] were employed in some form in a few studies. As in the case of CTN measurements, PEB was also recognized in certain articles by using qualitative interpretation (13\%). Certain used items were developed for the particular study (29\%) and one study utilized both a previous scale and its own measurement. Pro-environmental behaviour was mainly studied using self-reported scales, but a few studies also examined actual behaviours, for example when Soliman et al. [56] asked study participants to choose between a hard copy or an e-mail copy format, of which the electronic copy would be a pro-environmental choice.

\section{Approaches to Study Interconnection Between CTN and PEB}

We roughly categorized the approaches used to examine the relationship between $\mathrm{CTN}$ and PEB into four 
Table 1 Classification of approaches for studying the association between connectedness to nature and pro-environmental behaviour

\begin{tabular}{|c|c|c|}
\hline Approach & Brief description & Examples of reviewed study \\
\hline CTN and PEB as the main focus of study & $\begin{array}{l}\text { The articles focused mainly on the relationship } \\
\text { between human connection to nature and PEB. } \\
\text { The article did not look at other larger concepts. }\end{array}$ & $\begin{array}{l}\text { Black et al. [57], } \\
\text { Geng et al. [63], Gkargkavouzi et al. [64] }\end{array}$ \\
\hline $\begin{array}{l}\text { CTN and PEB as part of the wider } \\
\text { model or entity in the study }\end{array}$ & $\begin{array}{l}\text { The articles examined the association of CTN and } \\
\text { PEB as part of a wider concept such as part of } \\
\text { the hypothesis group or a mediating role of CTN. }\end{array}$ & $\begin{array}{l}\text { Forstmann and Sagioglou [59], Diessner et al. [65], } \\
\text { Scherer et al. [66] }\end{array}$ \\
\hline $\begin{array}{l}\text { Qualitative interpretation of } \\
\text { association between CTN and PEB }\end{array}$ & $\begin{array}{l}\text { The articles did not explicitly express measures of } \\
\text { CTN and PEB but addressed the association } \\
\text { between them using qualitative interpretation. }\end{array}$ & $\begin{array}{l}\text { Boiral et al. [60], Christie \& Waller [62], } \\
\text { Driscoll [67] }\end{array}$ \\
\hline $\begin{array}{l}\text { Exposure to nature and its association } \\
\text { to CTN and PEB }\end{array}$ & $\begin{array}{l}\text { The focus of the articles is the association between } \\
\text { exposure to nature and CTN and exposure to } \\
\text { nature and PEB. They do not directly measure the } \\
\text { link between CTN and PEB. }\end{array}$ & $\begin{array}{l}\text { Richardson et al. [61], Dopko et al. [68•], } \\
\text { Lynch et al. [69] }\end{array}$ \\
\hline
\end{tabular}

categories (Table 1). Below, we describe this categorization and give examples of studies in each category.

In the first category, the relationship between CTN and PEB was interpreted as the main research problem or focus of the article. For example, Black et al. [57] explored Australian suburb residents' attitudes and behaviours and indicated a strong association between CTN, attitudes towards conservation action and proconservation behaviour. Clark et al. [58] suggested that wildlife experiences connecting people with nature may enhance environmentally sustainable intentions. Thirteen percent of the articles were interpreted to belong to this category.

Most of the studies $(60 \%)$ fall into the second category, in which the relationship between CTN and PEB is addressed as part of a larger entity. A characteristic of this category is the relationship emerging as a hypothesis or as part of a model in which, for example, CTN acted as a mediator between independent and dependent (PEB) variables. Forstmann and Sagioglou [59] is an example of research in this category, as they found that one of the three nature relatedness dimensions mediated the relation between experience with classic psychedelic substances and PEB and stated that experiences with these substances may have lasting effects on the way people perceive nature and how strongly they commit to PEB (Table 2).

The third category (13\%) focuses on studies employing more qualitative methods. Articles that used a qualitative approach mostly did not explicitly express CTN and PEB measures. However, these articles clearly fulfilled the inclusion criteria, as they addressed the association between these concepts, and so, they were included in the review. For example, Boiral et al. [60] aimed to examine the significance, manifestations and practical effects of CTN in natural resource companies by interviewing environmental management experts. They stated that connectedness to nature represents an essential facet of environmental concerns for employees and may encourage environmental initiatives at the workplace.

A fourth category includes studies that explore ETN and its relations to CTN and PEB. For example, Richardson et al. [61] reported that engagement in nature activities in the 30-day campaign increased participants' connections to nature and their conservation behaviours but also produced improvements to participants' health and happiness.

Furthermore, even though CTN was used as a predictor of PEB in most of the articles, PEB was examined as a predictor of CTN in certain articles. For example, Christie and Waller [62] explored residents' experiences of participating in on-site composting (interpreted as PEB). With a combination of observation, interviews and focus groups, they found that involvement in composting increased the feelings of being connected to nature of some participants and added to their desire to create positive changes towards more sustainable surroundings.

We interpreted a certain degree of association between CTN and PEB from all the articles, excluding articles that only measured exposure relative to these concepts (the fourth category). However, the articles classified into the fourth category, in turn, indicated a link between ETN and CTN as well as between ETN and PEB. 


\section{Represented Natural Environments}

Out of all the articles reviewed, $48 \%$ explored actual exposure to some natural environment or nature activity either directly or indirectly. For example, Maguire et al. [70] studied peoples' encounters when swimming with humpback whales as an exposure to nature and found that, out of four factors, connection to nature emerged as the most important factor in predicting conservation intentions.

Out of the 23 articles in which people were actually exposed to nature, actual direct exposure was more common $(83 \%)$. Indirect exposure was measured in $17 \%$ of these articles. Direct exposure is illustrated, for example, by participants walking in nature [35], attending a national park tour [71] or gardening [72]. Indirect exposure to nature included, e.g. playing nature sounds in a supermarket [73] or showing a nature documentary to study participants [74]. Approximately half of the articles (52\%) explored the relations between CTN and PEB only on a theoretical level by examining peoples' perceptions based on their previous or general experiences in nature. In addition, we found one article that used both direct and indirect exposure to nature [35].

Forests played a very small role as natural environments in the reviewed articles; $60 \%$ of the studies did not deal with forests at any level. ${ }^{2}$ We interpreted the occurrence of forests in four different ways in the remaining articles mentioning forests. Firstly, forests were briefly mentioned in the intro of the study or when discussing the results with reference to a previous study or just by alluding to a forest (21\%). Secondly, forests also emerged in a few qualitative studies, in which interviewees briefly discussed them (6\%). The third inclusion method was when study participants were shown images or videos of natural environments that included forests $(6 \%)$. Lastly, forests appeared in a few studies $(6 \%)$ that measured participants' experiences after exposure to a forest, i.e. after spending time in a wooded environment. For example, Massingham et al. [75] explored which elements of ecotourism experiences at two destinations (a conservation-focused zoological park and a rainforest national park) are associated with an

\footnotetext{
${ }^{2}$ One statement by Mayer and Franz [6]: "Like a tree can be part of a forest, I feel embedded within the broader natural world" mentions forests as a part of the connectedness to nature measurement scale, but we did not interpret this statement to measure actual human connection to forests. A few other statements in other scales (e.g. [64]) were additionally not included, as they did not measure actual connectedness to forests. Nor did we include individual expressions of, e.g. trees that were mentioned a few times in the articles.
}

increase in conservation engagement and suggested that various ecotourism experiences may create different types of conservation engagement. However, even within this study, an animal encounter was the actual study focus and not so much the natural environment around it. Dopko et al. [68•] examined the potential benefits of a 4-h nature experience on children's moods, prosociality and attitudes towards nature after they spent time outdoors in a forest and nature school and indoors at an aviation and space museum. They found that children had more positive and negative emotions, a closer connection to nature and a greater willingness to protect nature after the forest and nature school experience.

\section{Discussion}

When looking at the number of publications that report or discuss the relationship between CTN and PEB, it is clear that the topic has been a popular research theme particularly over the past 5 years but also earlier. Even with our rather strict inclusion criteria, a total of 48 articles were included in our review that addressed the relationship between human connection to nature and PEB at some stage.

As expected, most of the research on CTN and PEB has occurred in developed countries, which indicates a need for wider geographical representation of the research. Concerning the studied populations, we did not find samples among the reviewed articles representing all age groups on a 5-year timeline. Furthermore, school children and adolescents had small representation in the studies. This is in line, e.g. with Whitburn et al. [12•], who concluded that adults have mainly been investigated concerning human connection to nature and PEB, although some evidence shows similar results concerning children. Some studies regarding children and adolescents were probably also left out from the reviewed sample as Scopus excludes, e.g. Children, Youth and Environment journal. In addition, our emphasis on quantitative measurement scales and constructs may have distorted our sample so that papers studying children have not been included. The instruments to examine these relationships have also been mainly developed for adults [76]. Thus, while the ethical aspects of the study must be borne in mind, studies on children and adults of the same family need more attention in future studies to explore how adults' attitudes towards nature affect childrens' perceptions and attitudes towards 
it, especially in the forest context. For example, in a longitudinal analysis, Evans et al. [77] showed that mothers' pro-environmental attitudes reflected in their childrens' environmentally friendly behaviours as young adults. On the other hand, influencing the attitudes of adults towards nature and environmental protection is difficult [78]. Childhood in particular is an important time for the development of a pro-environmental identity [79].

Concerning conceptual and methodological aspects, connectedness to nature was the most utilized term to describe human connection with nature. The Connectedness to Nature scale [6] was similarly the most popular measurement scale, as also indicated by previous studies [12•]. However, on the 5-year timeline of our data set, the CNS scale had not been utilized in any study that particularly mentioned having measured the relationship between people and forest. Consequently, this measurement scale could be applied and tested to measure human connectedness to forests.

The wider context of simultaneous ecosystem services (see, e.g. [80]) should be taken into account when measuring PEB. Research should focus on what types of forest use are considered to constitute PEB. For example, forest logging (provisioning services) may be interpreted as pro-environmental if the wood is used, e.g. as construction material to replace fossil raw materials. On the other hand, if we think of other ecosystem services, such as biodiversity (supporting services), then loggings cannot be considered PEB.

The findings from this review show that forests appear to be of very little weight or under-represented in CTN and PEB literature as an identified natural environment, with the exception of a few studies that actually measured experiences or perceptions of people after exposure to forests. However, forests may have been studied although they are not explicitly mentioned as nature environments. People's connections to nature increase as they are exposed to nature [35], but more research is needed on how various natural environments, such as forest types, affect this connection. As Wyles et al. [38] have indicated, some natural environments may be psychologically more beneficial compared with other environments. Future studies should distinguish between the natural environment types whose impacts are being measured. Thus, it would be interesting to study whether different natural environments have a different impact on PEB.

As most of the reviewed studies measured CTN only theoretically, without actual exposure to nature, it is impossible to say whether some survey participants, for example, considered forests or other natural environments as their natural form of exposure when answering the questionnaire. This certainly also depends on the recipient's geographical location and culture. Consequently, Restall and Conrad [2] suggested that CTN research is needed among various populations and cultures to understand the differences in how various groups understand the concept. Cultural aspects of connectedness to nature require more focus in future studies (see also [4•]).

People can notably also perceive forest differently. Some people perceive a wooded park as a forest, whereas others only classify an authentic untouched forest as a forest or alternatively a forest may be anything between these environments. As we assume that different nature environments affect the feeling of being connected to nature differently (see, e.g. [28]), exploring how different types of wooded environments affect the sense of connectedness and PEB is important. In addition, research should focus, e.g. on investigating citizen engagement to forests, especially in countries where forests play an important role. In particular, understanding how the human-forest relationship forms in countries where forests cover most of the land area could provide more insight into the actions that should be taken to foster the development of people's forest relationships. In Scandinavian countries particularly, we call for more qualitative approaches to explore the varieties of nature relationships, especially regarding forests, exposure to those environments and their associations to CTN and PEB. On the other hand, focusing narrowly on only certain environments may restrict, e.g. the generalizability and reliability of results too much. When examining nature relationships, more attention should also be paid to how the socio-economic background affects the opportunities to develop these relationships (see e.g. [11]). Furthermore, the definitions of nature relationship and forest relationship are also partly overlapping and the relationship between the two terms may be unclear. This also requires further research.

This literature review was conducted with limited search terms and using only the Scopus database. For example, due to the large number of literature that deals with the topic, a delineation had to be made of specific search terms. Thus, it is possible that some relevant articles have been dropped from the literature review at the abstract-reading stage if the connection between CTN and PEB was vague. 
Further, as many researchers have stated, the construct of connectedness to nature and other related constructs are multidimensional $[9,12,81]$. The purpose of this study was not to describe all the dimensions of CNT and PEB concepts or factors that affect CNT or are affected by it, but to scan the recent scientific discussion concerning the focal concepts and to identify future research agendas. The classification we formed that depicts associations between CTN and PEB is very general, and we acknowledge that it lacks the specific features of the reviewed studies. However, our intention was to include as many types of research as possible, so that the role of forests in research papers could also be clarified. All in all, the material utilized for this review would certainly allow for a more in-depth examination.

\section{Conclusions}

Based on the literature reviewed, we conclude that, based on the empirical studies, human-forest relationships have not been precisely defined in the scientific literature. Therefore, we interpret that forests as such are seen as a part of the larger human-nature relationship concept. However, especially in forested countries, the concept of nature may be a synonym for a forest, whereas the concept of nature may be something else in other cultural contexts. In addition, the human relationship with nature may vary or even be contradictory in countries where forests are also very important for the economy.

Multiple studies have depicted the link between human connectedness to nature and PEB. Thus, in forested countries, such as Finland, where forests are easily accessible, they may offer plenty of opportunities for increasing citizens' connections with nature, and consequently may lead to more PEB. A need therefore exists to find methods for increasing citizens' connectedness with nature.

Funding Open access funding provided by Natural Resources Institute Finland (LUKE). Dr. Häyrinen and Dr. Pynnönen received financial support from the Metsämiesten Säätiö foundation. Dr. Häyrinen also received funding from The Finnish Cultural Foundation.

\section{Compliance with Ethical Standards}

Conflict of Interest Häyrinen and Pynnönen declare no conflicts of interests.
Human and Animal Rights and Informed Consent This article does not contain any studies with human or animal subjects performed by any of the authors.

\section{Appendix 1}

Scopus search code

(TITLE-ABS-KEY ("connectedness to nature" AND "sustainable behavior" OR "pro-environmental" OR "pro-environmental behavior" OR proenvironmental OR consumption OR ecological OR "ecological behavior" OR conservation OR environmental OR "environmental behavior") OR TITLE-ABS-KEY ("connectedness to nature" AND "environmental identity" OR "environmentally friendly" OR "environmentally responsible") OR TITLE-ABS-KEY ("connection with nature" AND "sustainable behavior" OR "pro-environmental" OR "pro-environmental behavior" OR proenvironmental OR consumption OR ecological OR "ecological behavior" OR conservation OR environmental OR "environmental behavior") OR TITLE-ABS-KEY ("connection with nature" AND "environmental identity" OR "environmentally friendly" OR "environmentally responsible") OR TITLE-ABS-KEY ("nature connectedness" AND "sustainable behavior" OR "pro-environmental" OR "pro-environmental behavior" OR proenvironmental OR consumption OR ecological OR "ecological behavior" OR conservation OR environmental OR "environmental behavior") OR TITLE-ABS-KEY ("nature connectedness" AND "environmental identity" OR "environmentally friendly" OR "environmentally responsible") OR TITLE-ABS-KEY ("nature relatedness" AND "sustainable behavior" OR "pro-environmental" OR "pro-environmental behavior" OR proenvironmental OR consumption OR ecological OR "ecological behavior" OR conservation OR environmental OR "environmental behavior") OR TITLE-ABS-KEY ("nature relatedness" AND "environmental identity" OR "environmentally friendly" OR "environmentally responsible") OR TITLE-ABS-KEY ("connection to nature" AND "sustainable behavior" OR "pro-environmental" OR "pro-environmental behavior" OR proenvironmental OR consumption OR ecological OR "ecological behavior" OR conservation OR environmental OR "environmental behavior") OR TITLE-ABS-KEY ("connection to nature" AND "environmental identity" OR "environmentally friendly" OR "environmentally responsible")) AND PUBYEAR > 2014. 


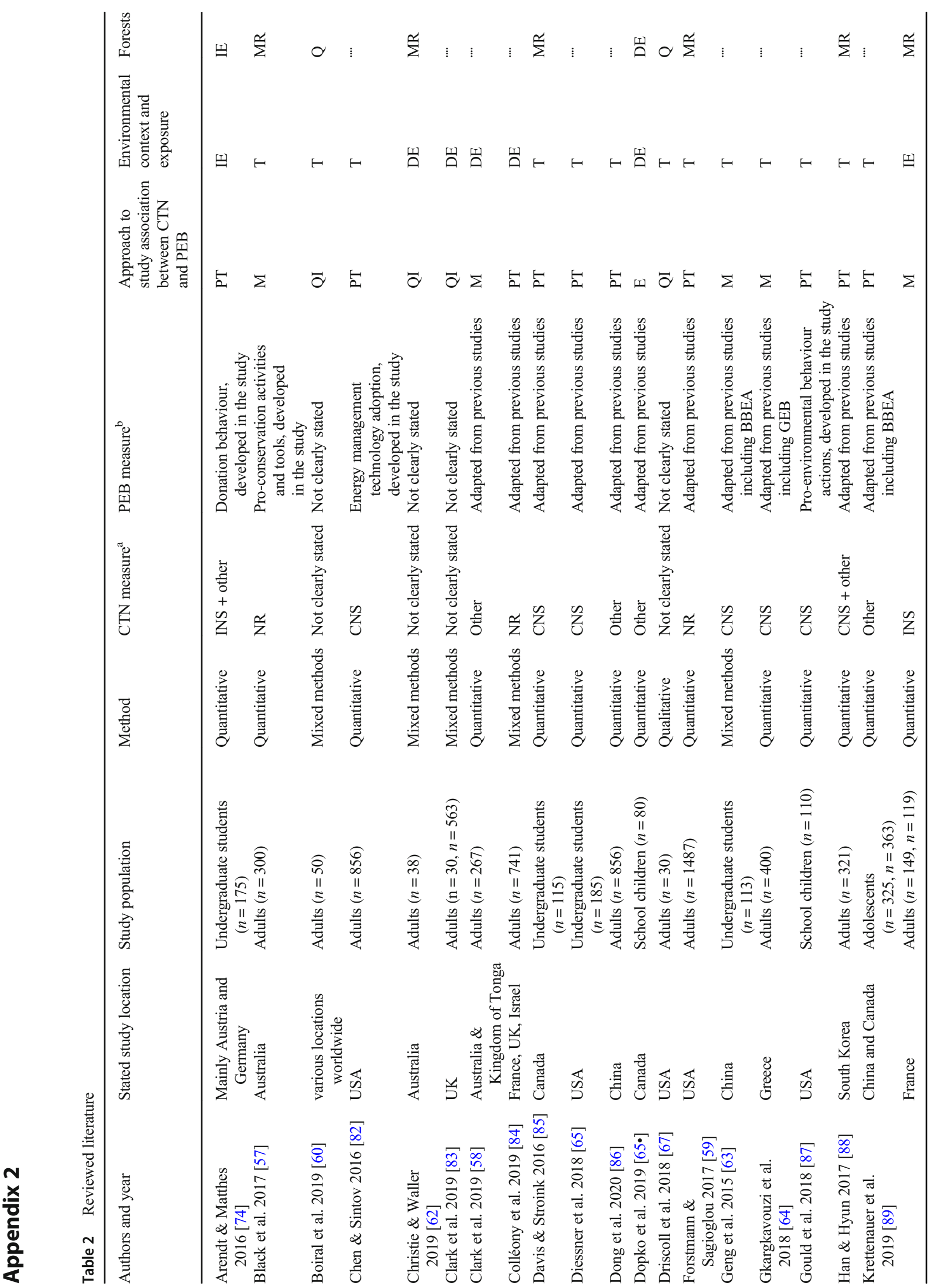




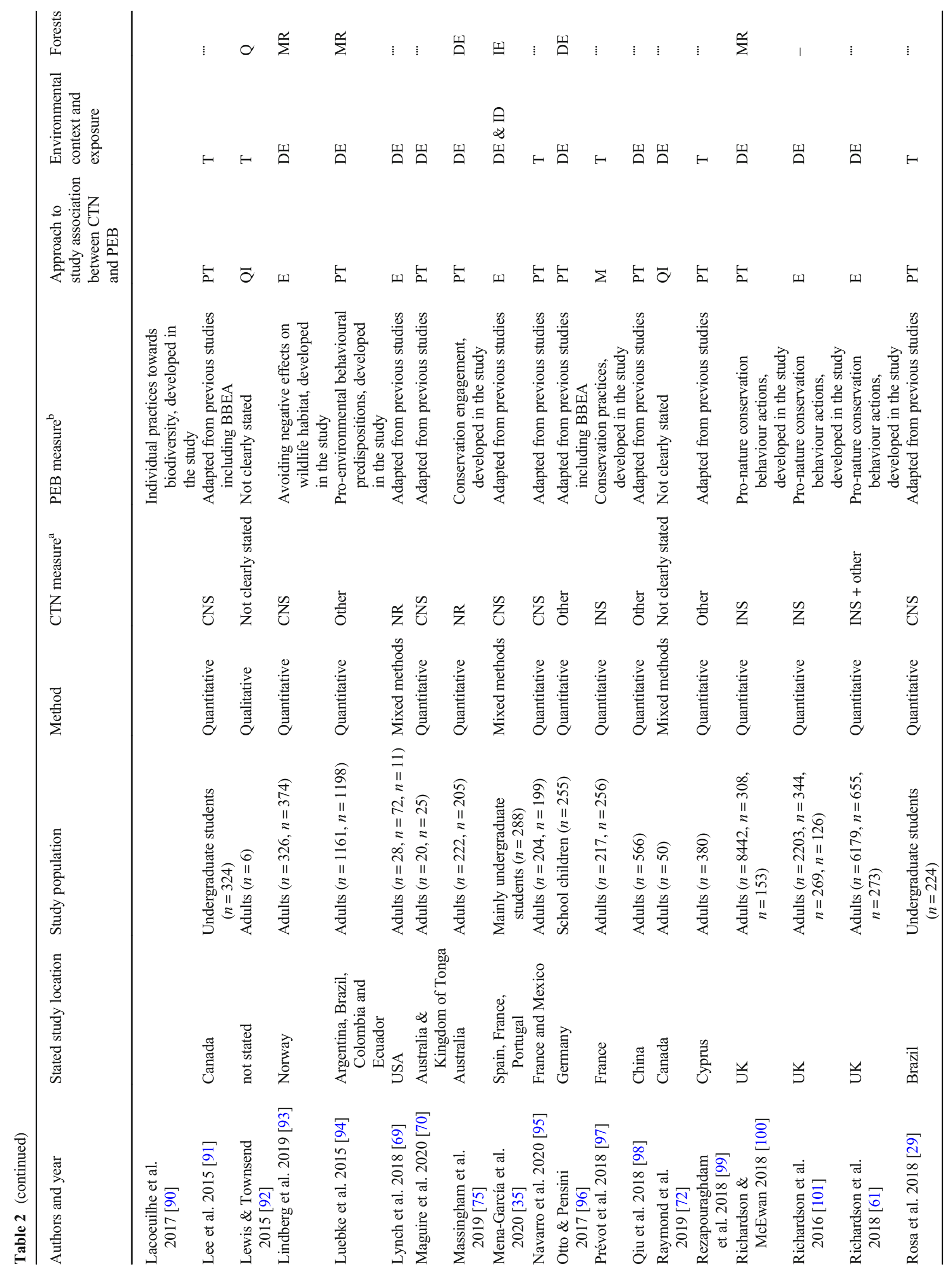




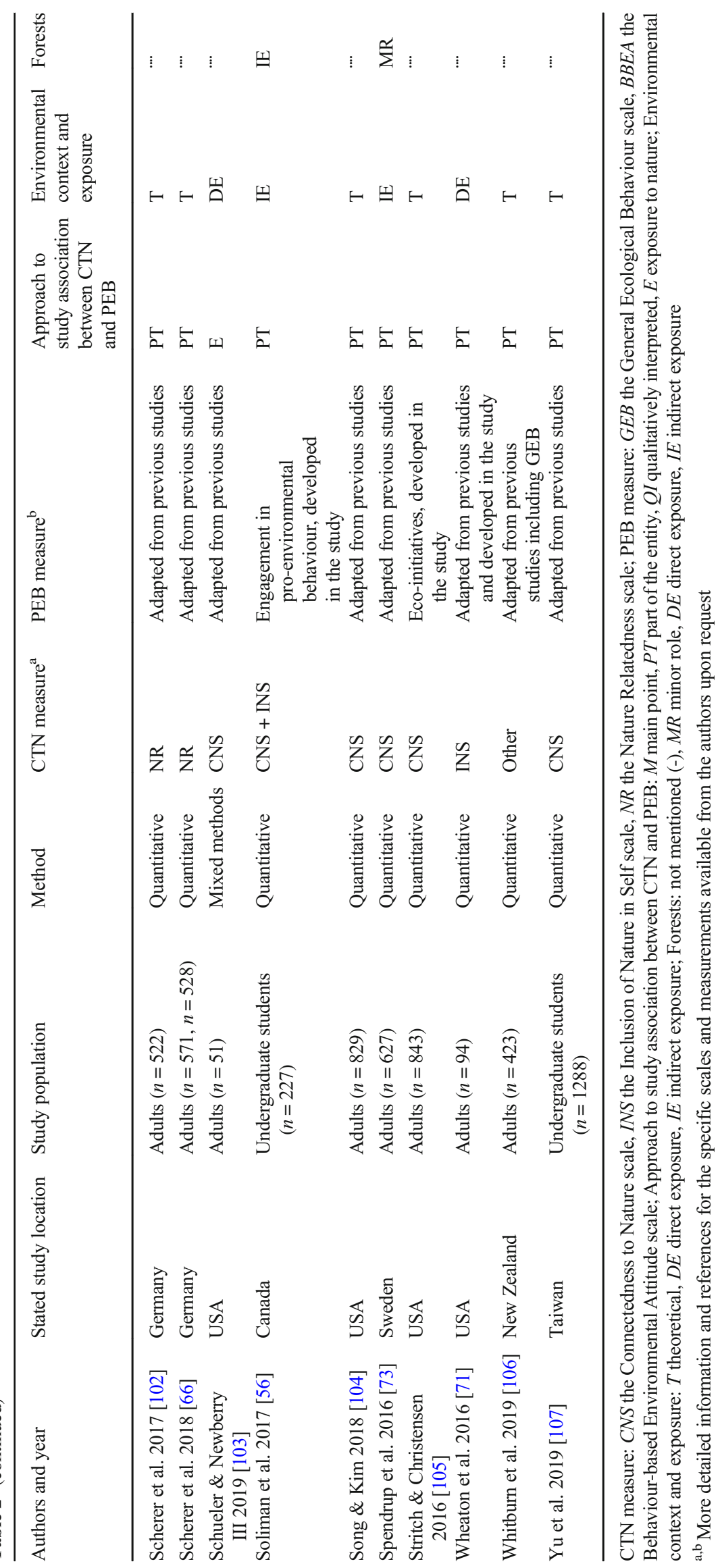


Open Access This article is licensed under a Creative Commons Attribution 4.0 International License, which permits use, sharing, adaptation, distribution and reproduction in any medium or format, as long as you give appropriate credit to the original author(s) and the source, provide a link to the Creative Commons licence, and indicate if changes were made. The images or other third party material in this article are included in the article's Creative Commons licence, unless indicated otherwise in a credit line to the material. If material is not included in the article's Creative Commons licence and your intended use is not permitted by statutory regulation or exceeds the permitted use, you will need to obtain permission directly from the copyright holder. To view a copy of this licence, visit http://creativecommons.org/licenses/by/4.0/.

\section{References}

Papers of particular interest, published recently, have been highlighted as:

- Of importance

1. Kals E, Schumacher D, Montada L. Emotional affinity toward nature as a motivational basis to protect nature. Environ Behav. 1999;31:178-202.

2. Restall B, Conrad E. A literature review of connectedness to nature and its potential for environmental management. J Environ Manag. 2015;159:264-78 Available from: https://www. sciencedirect.com/science/article/pii/S0301479715300748?via\% 3Dihub.

3. Tam K-P. Concepts and measures related to connection to nature: similarities and differences. J Environ Psychol. 2013;34:64-78 Available from: https:/www.sciencedirect.com/science/article/ pii/S0272494413000066.

4. Mackay CML, Schmitt MT. Do people who feel connected to nature do more to protect it? A meta-analysis. J Environ Psychol. 2019;65:101323. https://doi.org/10.1016/j.jenvp.2019. 101323 The recent meta-analysis provides an overview of research of whether subjective connection to nature promotes pro-environmental behaviour.

5. Gosling E, Williams KJH. Connectedness to nature, place attachment and conservation behaviour: testing connectedness theory among farmers. J Environ Psychol. 2010;30:298-304 Available from: https://www.sciencedirect.com/science/article/pii/ S027249441000006X.

6. Mayer FS, Frantz CM. The connectedness to nature scale: a measure of individuals' feeling in community with nature. J Environ Psychol. 2004;24:503-15 Available from: https://www. sciencedirect.com/science/article/pii/S0272494404000696.

7. Valkonen J. Johdanto. In: Valkonen J, Salonen T, editors. Reittejä luontosuhteeseen. Rovaniemi: Lapland University Press; 2013.

8. Nisbet EK, Zelenski JM, Murphy SA. The nature relatedness scale: linking individuals' connection with nature to environmental concern and behavior. Environ Behav. 2009;41:715-40. https://doi.org/10.1177/0013916508318748.

9. Schultz PW. Inclusion with nature: the psychology of humannature interactions. In: Schmuck P, Schultz PW, editors. Psychol Sustain Dev. Dordrecht: Kluwer Academic Publishers; 2002. p. 61-78.

10. Rossi L. Yksilöllä on väliä: Miten voisi tutkia yksilön elinikäistä ympäristösuhdetta. Elore. 2010;17:79-103.

11. Feygina I. Social justice and the human-environment relationship: common systemic, ideological, and psychological roots and processes. Soc Justice Res. 2013;26:363-81.
12. Whitburn J, Linklater W, Abrahamse W. Meta-analysis of human connection to nature and proenvironmental behavior. Conserv Biol. 2020;34:180-93 The article provides a comprehensive meta-analysis on human connection to nature and proenvironmental behaviour.

13. Clayton S. Environmental identity: a conceptual and operational definition. In: Clayton S, Opotow S, editors. Identity Nat Environ Psychol significance Nat. Cambridge: MIT Press; 2003. p. 45-65.

14. Perkins HE. Measuring love and care for nature. J Environ Psychol. 2010;30:455-63 Available from: http://www. sciencedirect.com/science/article/pii/S0272494410000551.

15. Dutcher DD, Finley JC, Luloff AE, Johnson JB. Connectivity with nature as a measure of environmental values. Environ Behav. 2007;39:474-93. https://doi.org/10.1177/0013916506298794.

16. Tam K-P. Dispositional empathy with nature. J Environ Psychol. 2013;35:92-104 Available from: http://www.sciencedirect.com/ science/article/pii/S0272494413000273.

17. Maloney MP, Ward MP, Braucht GN. A revised scale for measurement of ecological attitudes and knowledge. Am Psychol. 1975;30:787-90.

18. Kaiser FG. A general measure of ecological behavior. J Appl Soc Psychol. 1998;28:395-422.

19. Whitmarsh L, O'Neill S. Green identity, green living? The role of pro-environmental self-identity in determining consistency across diverse pro-environmental behaviours. J Environ Psychol. 2010;30:305-14 Available from: http://www.sciencedirect.com/ science/article/pii/S0272494410000046.

20. Fransson N, Gärling T. Environmental concern: conceptual definitions, measurement methods, and research findings. J Environ Psychol. 1999;19:369-82 Available from: http://www. sciencedirect.com/science/article/pii/S027249449990141X.

21. Dunlap RE, Jones RE. Environmental attitudes and values. In: Fernandez-Ballesteros R, editor. Encycl Psychol assess. London, Thousand Oaks, New Delhi: SAGE Publications Ltd; 2003. p. 364-9.

22. Olivos P, Aragonés JI. Psychometric properties of the environmental identity scale (EID). Psyecology. 2011;2:65-74.

23. Steg L, Vlek C. Encouraging pro-environmental behaviour: an integrative review and research agenda. J Environ Psychol. 2009;29:309-17 Available from: https://www.sciencedirect. com/science/article/pii/S0272494408000959.

24. Boldero J. The prediction of household recycling of newspapers: the role of attitudes, intentions, and situational factors. J Appl Soc Psychol. 1995;25:440-62.

25. Oreg S, Katz-Gerro T. Predicting proenvironmental behavior cross-nationally: values, the theory of planned behavior, and value-belief-norm theory. Environ Behav. 2006;38:462-83. https://doi.org/10.1177/0013916505286012.

26. Bamberg S, Möser G. Twenty years after Hines, Hungerford, and Tomera: a new meta-analysis of psycho-social determinants of pro-environmental behaviour. J Environ Psychol. 2007;27:14-25 Available from: http://www.sciencedirect.com/science/article/ pii/S0272494406000909.

27. Rosa CD, Collado S. Experiences in nature and environmental attitudes and behaviors: setting the ground for future research. Front Psychol. 2019;10:1-9 The review article provides an overview of the links between peoples' nature experiences, environmental attitudes, and behaviours.

28. Martin L, White MP, Hunt A, Richardson M, Pahl S, Burt J. Nature contact, nature connectedness and associations with health, wellbeing and pro-environmental behaviours. J Environ Psychol. 2020;68:101389 Available from: http://www.sciencedirect.com/ science/article/pii/S0272494419301185.

29. Rosa CD, Profice CC, Collado S. Nature experiences and adults' self-reported pro-environmental behaviors: the role of 
connectedness to nature and childhood nature experiences. Front Psychol. 2018;9:1-10.

30. Larson LR, Whiting JW, Green GT. Exploring the influence of outdoor recreation participation on pro-environmental behaviour in a demographically diverse population. Local Environ. 2011;16: 67-86. https://doi.org/10.1080/13549839.2010.548373.

31. Pensini P, Horn E, Caltabiano N. An exploration of the relationships between adults' childhood and current nature exposure and their mental well-being. Child Youth Environ. 2016;26:125-47.

32. Mayer FS, Frantz CMP, Bruehlman-Senecal E, Dolliver K. Why is nature beneficial? The role of connectedness to nature. Environ Behav. 2009;41:607-43.

33. Ulrich RS, Simons RF, Losito BD, Fiorito E, Miles MA, Zelson M. Stress recovery during exposure to natural and urban environments. J Environ Psychol. 1991;11:201-30 Available from: http://www.sciencedirect.com/science/article/pii/ S0272494405801847.

34. Howell AJ, Dopko RL, Passmore H-A, Buro K. Nature connectedness: associations with well-being and mindfulness. Pers Individ Dif. 2011;51:166-71 Available from: http://www. sciencedirect.com/science/article/pii/S0191886911001711.

35. Mena-García A, Olivos P, Loureiro A, Navarro O. Effects of contact with nature on connectedness, environmental identity and evoked contents. PsyEcol. 2020;11:21-36. https://doi.org/10. 1080/21711976.2019.1643663.

36. Capaldi CA, Dopko RL, Zelenski JM. The relationship between nature connectedness and happiness: a meta-analysis. Front Psychol. 2014;5:976 Available from: http://www.ncbi.nlm.nih. gov/pubmed/25249992.

37. Pritchard A, Richardson M, Sheffield D, McEwan K. The relationship between nature connectedness and eudaimonic well-being: a meta-analysis. J Happiness Stud Springer Netherlands. 2020;21:1145-67. https://doi.org/10.1007/s10902-019-00118-6.

38. Wyles KJ, White MP, Hattam C, Pahl S, King H, Austen M. Are some natural environments more psychologically beneficial than others? The importance of type and quality on connectedness to nature and psychological restoration. Environ Behav. 2019;51: 111-43. Available from:. https://doi.org/10.1177/ 0013916517738312

39. Ahponen P. Metsä elämäntavassa. Silva Fenn. 1987;21:397-404.

40. Laurén K. Suo - sisulla ja sydämellä - Suomalaisten suokokemukset ja -kertomukset kulttuurisen luontosuhteen ilmentäjinä. [Helsinki]: Suomalaisen Kirjallisuuden Seura; 2006.

41. Hansmann R, Hug S-M, Seeland K. Restoration and stress relief through physical activities in forests and parks. Urban For Urban Green. 2007;6:213-25 Available from: http://www. sciencedirect.com/science/article/pii/S1618866707000623.

42. Tyrväinen L, Ojala A, Korpela K, Lanki T, Tsunetsugu Y, Kagawa $\mathrm{T}$. The influence of urban green environments on stress relief measures: a field experiment. J Environ Psychol. 2014;38: 1-9 Available from: https://doi.org/10.1016/j.jenvp.2013.12. 005.

43. Tsunetsugu Y, Lee J, Park BJ, Tyrväinen L, Kagawa T, Miyazaki Y. Physiological and psychological effects of viewing urban forest landscapes assessed by multiple measurements. Landsc Urban Plan. 2013;113:90-3. https://doi.org/10.1016/j.landurbplan.2013. 01.014 .

44. Nord M, Luloff AE, Bridger JC. The association of forest recreation with environmentalism. Environ Behav. 1998;30:235-46.

45. Häyrinen L, Mattila O, Berghäll S, Toppinen A. Lifestyle of health and sustainability of forest owners as an indicator of multiple use of forests. For Policy Econ. 2016;67:10-9. https://doi.org/10. 1016/j.forpol.2016.03.005.

46. Vining J, Merrick MS, Price EA. The distinction between humans and nature: human perceptions of connectedness to nature and elements of the natural and unnatural. Hum Ecol Rev. 2008;15: $1-11$.

47. Fink A. Conducting research literature reviews: from the Internet to paper. 2nd ed. Thousand Oaks, California: Sage Publications; 2005.

48. Petticrew M, Roberts H. Systematic reviews in the social sciences: a practical guide: Blackwell Publishing Ltd; 2006.

49. Downe-Wamboldt B. Content analysis: method, applications, and issues. Health Care Women Int. 1992;13:313-21. https://doi.org/ 10.1080/07399339209516006.

50. White MD, Marsh EE. Content analysis: a flexible methodology. Libr Trends. 2006;55:22-45.

51. Schultz PW. The structure of environmental concern: concern for self, other people, and the biosphere. J Environ Psychol. 2001;21: 327-39 Available from: http:/www.sciencedirect.com/science/ article/pii/S0272494401902270.

52. Nisbet EK, Zelenski JM. The NR-6: a new brief measure of nature relatedness. Front Psychol. 2013;4:1-11.

53. Brügger A, Kaiser FG, Rochen N. One for all? Connectedness to nature, inclusion of nature, environmental identity, and implicit association with nature. Eur Psychol. 2011;16:324-33.

54. Kaiser FG, Wilson M. Goal-directed conservation behavior: the specific composition of a general performance. Pers Individ Dif. 2004;36:1531-44 Available from: http://www.sciencedirect. com/science/article/pii/S0191886903002460.

55. Kaiser FG, Oerke B, Bogner FX. Behavior-based environmental attitude: development of an instrument for adolescents. J Environ Psychol. 2007;27:242-51 Available from: http://www. sciencedirect.com/science/article/pii/S0272494407000497.

56. Soliman M, Peetz J, Davydenko M. The impact of immersive technology on nature relatedness and pro-environmental behavior. J Media Psychol. 2017;29:8-17.

57. Black R, Laird SG, Perez-Mujica L. Using residents' attitudes, knowledge and behaviours to improve biodiversity conservation in an Australian rural-urban landscape. Rural Soc. 2017;26:197209.

58. Clark E, Mulgrew K, Kannis-Dymand L, Schaffer V, Hoberg R. Theory of planned behaviour: predicting tourists' proenvironmental intentions after a humpback whale encounter. J Sustain Tour. 2019;27:649-67. https://doi.org/10.1080/ 09669582.2019 .1603237

59. Forstmann M, Sagioglou C. Lifetime experience with (classic) psychedelics predicts pro-environmental behavior through an increase in nature relatedness. J Psychopharmacol. 2017;31:975-88.

60. Boiral O, Heras-Saizarbitoria, Iñaki Brotherton M. Nature connectedness and environmental management in natural resources companies: an exploratory study. J Clean Prod J. 2019;206:22737.

61. Richardson M, Mcewan K, Garip G. 30 days wild: who benefits most? J Public Ment Health. 2018;17:95-104.

62. Christie B, Waller V. Community learnings through residential composting in apartment buildings. J Environ Educ. 2019;50: 97-112. https://doi.org/10.1080/00958964.2018.1509289.

63. Geng L, Xu J, Ye L, Zhou W, Zhou K. Connections with nature and environmental behaviors. PLoS One. 2015;10:1-12. https:// doi.org/10.1371/journal.pone.0127247.

64. Gkargkavouzi A, Paraskevopoulos S, Matsiori S. Who cares about the environment? J Hum Behav Soc Environ. 2018;28:746-57.

65. Diessner R, Genthôs R, Praest K, Pohling R. Identifying with nature mediates the influence of valuing nature's beauty on proenvironmental behaviors. Ecopsychol. 2018;10:97-105. https://doi.org/10.1089/eco.2017.0040.

66. Scherer C, Emberger-Klein A, Menrad K. Segmentation of interested and less interested consumers in sports equipment made of bio-based plastic. Sustain Prod Consum. 2018;14:53-65. https:// doi.org/10.1016/j.spc.2018.01.003. 
67. Driscoll D. Beyond organizational ties: foundations of persistent commitment in environmental activism. Soc Mov Stud. 2018;17: 697-715. https://doi.org/10.1080/14742837.2018.1519412.

68. Dopko RL, Capaldi CA, Zelenski JM. The psychological and social benefits of a nature experience for children: a preliminary investigation. J Environ Psychol. 2019;63:134-8. https://doi.org/ 10.1016/j.jenvp.2019.05.002 The study presents an analysis of the effects caused by a short nature experience on children's attitudes towards nature. This was the only study among the reviewed articles in which children comprised the study population and forest was concurrently defined as a natural environment.

69. Lynch LI, Dauer JM, Babchuk WA, Heng-Moss T, Golick D. In their own words: the significance of participant perceptions in assessing entomology citizen science learning outcomes using a mixed methods approach. Insects [Internet]. 2018;9. Available from: https://pubmed.ncbi.nlm.nih.gov/29415522

70. Maguire P, Kannis-dymand L, Mulgrew KE, Schaffer V, Peake S. Empathy and experience: understanding tourists' swim with whale encounters. Hum Dimens Wildl. 2020;25:105-20. https:// doi.org/10.1080/10871209.2019.1695024.

71. Wheaton M, Ardoin NM, Hunt C, Schuh JS, Kresse M, Menke C, et al. Using web and mobile technology to motivate proenvironmental action after a nature-based tourism experience. J Sustain Tour. 2016;24:594-615. https://doi.org/10.1080/ 09669582.2015.1081600.

72. Raymond CM, Diduck AP, Buijs A, Boerchers M, Moquin R. Exploring the co-benefits (and costs) of home gardening for biodiversity conservation biodiversity conservation. Local Environ. 2019;24:258-73.

73. Spendrup S, Hunter E, Isgren E. Exploring the relationship between nature sounds, connectedness to nature, mood and willingness to buy sustainable food: a retail field experiment. Appetite. 2016;100:133-41. https://doi.org/10.1016/j.appet.2016.02.007.

74. Arendt F, Matthes J. Nature documentaries, connectedness to nature, and pro-environmental behavior. Environ Commun. 2016;10:453-72. https://doi.org/10.1080/17524032.2014. 993415.

75. Massingham E, Fuller RA, Dean AJ. Pathways between contrasting ecotourism experiences and conservation engagement. Biodivers Conserv. 2019;28:827-45. https://doi.org/10.1007/ s10531-018-01694-4.

76. Hughes J, Richardson M, Lumber R. Evaluating connection to nature and the relationship with conservation behaviour in children. J Nat Conserv. 2018;45:11-9. https://doi.org/10.1016/j.jnc. 2018.07.004.

77. Evans GW, Otto S, Kaiser FG. Childhood origins of young adult environmental behavior. Psychol Sci. 2018;29:679-87.

78. Kaiser FG, Brügger A, Hartig T, Bogner FX, Gutscher H. Appreciation of nature and appreciation of environmental protection: how stable are these attitudes and which comes first? Eur Rev Appl Psychol. 2014;64:269-77.

79. Chawla L. Childhood experiences associated with care for the natural world: a theoretical framework for empirical results. Child Youth Environ. 2007;17:144-70 Available from: http:// www.jstor.org/stable/10.7721/chilyoutenvi.17.4.0144\% 5Cnhttp://about.jstor.org/terms.

80. Millennium Ecosystem Assessment. Ecosystems and human wellbeing: synthesis [Internet]. Washington, DC; 2005. Available from: http://www.who.int/entity/globalchange/ecosystems/ ecosys.pdf\%5Cnhttp://chapter.ser.org/europe/files/2012/08/ Harris.pdf

81. Schultz PW, Shriver C, Tabanico JJ, Khazian AM. Implicit connections with nature. J Environ Psychol. 2004;24:31-42.

82. Chen B, Sintov N. Bridging the gap between sustainable technology adoption and protecting natural resources: predicting intentions to adopt energy management technologies in California. Chem Phys Lett. 2016;22:210-23. https://doi.org/10. 1016/j.erss.2016.10.003.

83. Clark DN, Jones DN, Reynolds SJ. Exploring the motivations for garden bird feeding in south-East England. Ecol Soc. 2019;24.

84. Colléony A, White R, Shwartz A. The influence of spending time outside on experience of nature and environmental attitudes. Landsc Urban Plan. 2019;187:96-104 Available from: http:/ www.sciencedirect.com/science/article/pii/S0169204618313975.

85. Davis AC, Stroink ML. Within-culture differences in self-construal, environmental concern, and proenvironmental behavior. Ecopsychology. 2016;8:64-73.

86. Dong X, Liu S, Li H, Yang Z, Liang S, Deng N. Love of nature as a mediator between connectedness to nature and sustainable consumption behavior. J Clean Prod. 2020;2020:242. https://doi.org/ 10.1016/j.jclepro.2019.118451.

87. Gould RK, Krymkowski DH, Ardoin NM. The importance of culture in predicting environmental behavior in middle school students on Hawai' 1 island. PLoS One. 2018;13:1-16.

88. Han H, Hyun SS. Fostering customers' pro-environmental behavior at a museum. J Sustain Tour. 2017;25:1240-56. https://doi.org/ 10.1080/09669582.2016.1259318.

89. Krettenauer T, Wang W, Jia F, Yao Y. Connectedness with nature and the decline of pro-environmental behavior in adolescence: a comparison of Canada and China. J Environ Psychol [Internet]. 2019; Available from: https://doi.org/10.1016/j.jenvp.2019. 101348

90. Lacoeuilhe A, Prévot A, Shwartz A. The social value of conservation initiatives in the workplace. Landsc Urban Plan. 2017;157: 493-501. https://doi.org/10.1016/j.landurbplan.2016.08.019.

91. Lee K, Ashton MC, Choi J, Zachariassen K. Connectedness to nature and to humanity: their association and personality correlates $2015 ; 6$.

92. Lewis M, Townsend M. 'Ecological embeddedness' and its public health implications: findings from an exploratory study. Ecohealth. 2015;12:244-52. https://doi.org/10.1007/s10393-0140987-y.

93. Lindberg K, Veisten K, Halse AH. Analyzing the deeper motivations for nature-based tourism facility demand: a hybrid choice model of preferences for a reindeer visitor center 2019;19:157174.

94. Luebke JF, Clayton S, Kelly LD, Grajal A. Global climate change attitudes and perceptions among South American Zoo Visitors 2015;393:385-393.

95. Navarro O, Tapia-Fonllem C, Fraijo-sing B, Roussiau N, Bilingüe $\mathrm{R}$, Ambiental DP, et al. Connectedness to nature and its relationship with spirituality, wellbeing and sustainable behaviour. PsyEcol. 2020;11:37-48. https://doi.org/10.1080/21711976. 2019.1643662.

96. Otto S, Pensini P. Nature-based environmental education of children: environmental knowledge and connectedness to nature, together, are related to ecological behaviour. Glob Environ Chang. 2017;47:88-94 Available from: https://www.sciencedirect.com/ science/article/pii/S0959378016305787.

97. Prévot A, Cheval H, Raymond R, Cosquer A. Routine experiences of nature in cities can increase personal commitment toward biodiversity conservation. Biol Conserv. 2018;226:1-8. https://doi. org/10.1016/j.biocon.2018.07.008.

98. Qiu M, Zhang J, Zheng C. Exploring tourists' soundscape emotion and its impact on sustainable tourism development. Asia Pacific J Tour Res. 2018;23:862-79.

99. Rezapouraghdam H, Alipour H, Darvishmotevali M. Employee workplace spirituality and pro-environmental behavior in the hotel industry. J Sustain Tour. 2018;26:740-58. 
100. Richardson M, McEwan K. 30 days wild and the relationships between engagement with nature's beauty. Nature Connectedness Well-Being Front Psychol. 2018;9:1-9.

101. Richardson M, Cormack A, McRobert L, Underhill R. 30 days wild: development and evaluation of a large-scale nature engagement campaign to improve well-being. PLoS One. 2016;11: e0149777.

102. Scherer C, Emberger-Klein A, Menrad K. Biogenic product alternatives for children: consumer preferences for a set of sand toys made of bio-based plastic. Sustain Prod Consum. 2017;10:1-14. https://doi.org/10.1016/j.spc.2016.11.001.

103. Schueler DS, Newberry MG III. Animal ambassador interpretation techniques and its impact on connectedness to nature. Appl Environ Educ Commun. 2020;2019:1-15. https://doi.org/10. 1080/1533015X.2019.1586596.

104. Song SY, Kim Y-K. A human-centered approach to green apparel advertising: decision tree predictive modeling of consumer choice. Sustainability. 2018;10:1-20.
105. Stritch JM, Christensen RK. Going green in public organizations: linking organizational commitment and public service motives to public employees' workplace eco-initiatives. Am Rev Public Adm. 2016;46:337-55.

106. Whitburn J, Linklater WL, Milfont TL. Exposure to urban nature and tree planting are related to pro-environmental behavior via connection to nature, the use of nature for psychological restoration, and environmental attitudes. Environ Behav. 2019;51:787810.

107. Yu T-K, Lin F, Kao K-Y, Yu T-Y. Encouraging environmental commitment to sustainability: an empirical study of environmental connectedness theory to undergraduate students. Sustainability. 2019;11:1-21.

Publisher's Note Springer Nature remains neutral with regard to jurisdictional claims in published maps and institutional affiliations. 